\title{
Prospective, randomized, multicenter study with 2-year follow-up to compare the performance of decompression with and without interlaminar stabilization
}

\author{
Sven Schmidt, MD, Joerg Franke, MD, ${ }^{2}$ Michael Rauschmann, MD, ${ }^{1}$ Dieter Adelt, MD, ${ }^{3}$ \\ Matteo Mario Bonsanto, MD, ${ }^{4}$ and Steffen Sola, MD ${ }^{5}$
}

${ }^{1}$ Orthopädische Universitätsklinik, Frankfurt; ${ }^{2}$ Klinikum Magdeburg; ${ }^{3 P a r a c e l s u s k l i n i k ~ H e n s t e d t-U l z b u r g ; ~}{ }^{4}$ Universitätsklinikum Schleswig-Holstein Klinik für Neurochirurgie, Lubeck; and ${ }^{5}$ Chirurgische Universitätsklinik Rostock, Germany

\begin{abstract}
OBJECTIVE Surgical decompression is extremely effective in relieving pain and symptoms due to lumbar spinal stenosis (LSS). Decompression with interlaminar stabilization (D+ILS) is as effective as decompression with posterolateral fusion for stenosis, as shown in a major US FDA pivotal trial. This study reports a multicenter, randomized controlled trial in which D+ILS was compared with decompression alone (DA) for treatment of moderate to severe LSS.
\end{abstract}

METHODS Under approved institutional ethics review, 230 patients (1:1 ratio) randomized to either DA or D+ILS (coflex, Paradigm Spine) were treated at 7 sites in Germany. Patients had moderate to severe LSS at 1 or 2 adjacent segments from L-3 to L-5. Outcomes were evaluated up to 2 years postoperatively, including Oswestry Disability Index (ODI) scores, the presence of secondary surgery or lumbar injections, neurological status, and the presence of device- or procedure-related severe adverse events. The composite clinical success (CCS) was defined as combining all 4 of these outcomes, a success definition validated in a US FDA pivotal trial. Additional secondary end points included visual analog scale (VAS) scores, Zürich Claudication Questionnaire (ZCQ) scores, narcotic usage, walking tolerance, and radiographs.

RESULTS The overall follow-up rate was $91 \%$ at 2 years. There were no significant differences in patient-reported outcomes at 24 months $(p>0.05)$. The CCS was superior for the $D+I L S$ arm $(p=0.017)$. The risk of secondary intervention was 1.75 times higher among patients in the DA group than among those in the D+ILS group $(p=0.055)$. The DA arm had $228 \%$ more lumbar injections (4.5\% for D+ILS vs $14.8 \%$ for DA; $p=0.0065)$ than the D+ILS one. Patients who underwent DA had a numerically higher rate of narcotic use at every time point postsurgically $(16.7 \%$ for D+ILS vs $23 \%$ for DA at 24 months). Walking Distance Test results were statistically significantly different from baseline; the D+ILS group had $>2$ times the improvement of the DA. The patients who underwent D+ILS had > 5 times the improvement from baseline compared with only 2 times the improvement from baseline for the DA group. Foraminal height and disc height were largely maintained in patients who underwent D+ILS, whereas patients treated with DA showed a significant decrease at 24 months postoperatively $(p<0.001)$.

CONCLUSIONS This study showed no significant difference in the individual patient-reported outcomes (e.g., ODI, VAS, ZCQ) between the treatments when viewed in isolation. The CCS (survivorship, ODI success, absence of neurological deterioration or device- or procedure-related severe adverse events) is statistically superior for ILS. Microsurgical D+ILS increases walking distance, decreases compensatory pain management, and maintains radiographic foraminal height, extending the durability and sustainability of a decompression procedure.

Clinical trial registration no.: NCT01316211 (clinicaltrials.gov)

https://thejns.org/doi/abs/10.3171/2017.11.SPINE17643

KEY WORDS spinal stenosis; microsurgical decompression; interlaminar stabilization; lumbar; trauma

ABBREVIATIONS AE = adverse event; $\mathrm{BMI}=$ body mass index; $\mathrm{CCS}=$ composite clinical success; $\mathrm{DA}=$ decompression alone; $\mathrm{DH}=$ disc height; $\mathrm{D}+\mathrm{ILS}=$ decompression with interlaminar stabilization; DPR SAE = device- or procedure-related severe AE; FH = foraminal height; $\mathrm{LI}$ = lumbar injection; LSS = lumbar spinal stenosis; ODI = Oswestry Disability Index; PF = physical function; PRO = patient-reported outcome; PS = patient satisfaction; $S \mathrm{~S}$ = symptom severity; $\mathrm{SSI}=$ secondary surgical intervention; VAS = visual analog scale; WDT = Walking Distance Test; ZCQ = Zürich Claudication Questionnaire

SUBMITTED June 19, 2017. ACCEPTED November 21, 2017.

INCLUDE WHEN CITING Published online January 26, 2018; DOI: 10.3171/2017.11.SPINE17643. 
$\mathrm{F}$ OR the last 50 years, decompression surgery has been the standard of care for the amelioration of neurocompressive disease, or spinal stenosis, which is a degenerative disease generally regarded as part of the aging process, with progressive and debilitating symptomatology leading to significant compromise of activities of daily living. ${ }^{3}$ Although extremely effective clinically, decompression surgery does not arrest the disease progression, but rather addresses the presenting clinical symptoms. Even with surgical intervention, over time the functional quality of life may be affected because the disease progression may cause a recurrence of symptoms. Recent articles $7,8,14,22$ have elucidated that neither current surgical treatment options of decompression surgery nor decompression surgery with fusion ${ }^{5,20}$ is able to adequately address the full continuum of spinal stenosis. ${ }^{18,19}$

The progressive nature of lumbar degenerative pathology can be multifactorial, with significant contribution from degenerative facets and from other sources of pathology. Many clinicians debate whether simple microsurgical decompression is enough to relieve symptoms in the long term, and have compared this procedure to performing posterior lumbar fusion. ${ }^{10,13,17}$ This has led to a significant increase in the rates of fusion procedures performed after decompression procedures, and has raised some concern about overuse of this technology to support degenerative spinal segments. ${ }^{7}$ Modhia et al. ${ }^{14}$ showed readmission rates of $8 \%-10 \%$ per year after failed microsurgical decompression resulting in either conversion to fusion, revision decompression, or injections. Furthermore, of those patients who were not readmitted, $>25 \%$ received injections for pain management within the first quarter and $20 \%$ received injections in the second quarter postoperatively. ${ }^{11}$ Similarly, the Spine Patient Outcomes Research Trial (SPORT) reported reoperation rates ranging from $8 \%$ at 2 years to $13 \%$ at 4 years in the patients who underwent decompression. ${ }^{22}$ Recently, Ghogawala et al. ${ }^{8}$ prospectively studied patients with stable spondylolisthesis and found a cumulative reoperation rate of $34 \%$ in the decompression alone (DA) group.

In addition to the complex presentation of degenerative lumbar spinal stenosis (LSS), validated patient-reported outcomes (PROs) may not adequately reflect short-term and long-term intended clinical benefit from a single outcome measure. ${ }^{1}$ The PROs are known to be affected by psychosocial covariates and the psychometric properties of the tests themselves. ${ }^{23}$ Regardless of treatment, the primary end point goal of spinal stenosis surgery is to produce a sustainable treatment outcome without requiring reoperations or further epidural interventions. ${ }^{9}$ The rationale for including epidural interventions as a criterion of the primary end point signifies a definitive, empirical measure of insufficient decompression at the time of surgery or progression of the degeneration, causing recurrence. Either way, the surgery failed to provide sustained pain relief. When assessing clinical success for a spinal stenosis diagnosis, PROs focused on quantifying back and leg pain, function, and satisfaction as, in addition to their neurological function, freedom from pain medication, and ability to walk incrementally describe the patient's overall clinical success. Therefore, most spine clinical trials per- formed in the US as part of an approval process through the FDA use a composite clinical success (CCS) score that is a combination of multiple safety and efficacy end points to describe both safety and efficacy comprehensively.

The objective of this report was to present the results of a 2-year prospective, randomized, multicenter study comparing open microsurgical DA with open microsurgical decompression with interlaminar stabilization (D+ILS) in patients with moderate to severe LSS with or without spondylolisthesis at 1 or 2 contiguous levels between L-3 and L-5.

\section{Methods \\ Study Design}

Patients underwent surgery between March 2008 and July 2014 at 1 of 7 sites throughout Germany, with approval of the institutional ethics committee. The planned randomization was a 1:1 ratio for a total of 230 patients (115 investigational and 115 control). The control group was open microsurgical DA, and the investigational group consisted of patients who underwent open microsurgical D+ILS, using the coflex device (Paradigm Spine). Each center received a batch of sealed, numbered, randomization envelopes, and neither patients nor surgeons knew the study treatment until time of surgery. This study was registered with the ClinicalTrials.gov database (http:// clinicaltrials.gov), and its registration no. is NCT01316211. All patients had a minimum of 3 months of conservative therapy without improvement of symptoms, and required open microsurgical decompression for treatment of moderate to severe LSS. Screening for the inclusion/exclusion criteria was performed prior to enrollment (Table 1).

Briefly, the major inclusion criteria were age $>40$ years, visual analog scale (VAS) back pain score of $\geq 50 \mathrm{~mm}$, and radiographic confirmation of clinical symptoms of at least moderate degenerative spinal stenosis, with constriction of the central spinal canal in 1 or 2 adjacent segments from L-3 to L-5 with the need for decompression. In addition, the following was allowed but not required: hypertrophy of the facet joints and subarticular recess stenosis in the relevant segment or stenosis of the foramen in the relevant segment, and/or spondylolisthesis (anterolisthesis or retrolisthesis) up to grade I verified by flexion-extension radiographic films. The main exclusion criteria were radiographic confirmation of translational instability in the main segment as well as in adjacent segments (dynamic translational instability $\leq 3 \mathrm{~mm}$ ), previous surgery at index level, and/or vertebral or pars fracture.

\section{Data Analysis}

Analyses were performed using a modified intent-totreat analysis set that included a total of 110 patients with D+ILS and 115 patients with DA. There were 264 patients screened and 254 were randomized. Of these, 250 had a complete surgical case report form with baseline data sufficient for inclusion in the modified intent-to-treat analysis set and subsequent data collection and analysis. Four patients did not have a complete case report form at the time of enrollment, due to loss after randomization, not meeting inclusion/exclusion criteria, or other factors. 
TABLE 1. Inclusion and exclusion requirements

\begin{tabular}{|c|c|}
\hline Inclusion Criteria & Exclusion Criteria \\
\hline Age $>40$ yrs & Any of the following will exclude a patient from the study: \\
\hline $\begin{array}{l}\text { Radiographic confirmation of clinical symptoms of at least moderate } \\
\text { degenerative spinal stenosis, w/ constriction of the central spinal } \\
\text { canal of } 1 \text { or } 2 \text { adjacent segments in the L3-5 region w/ the need }\end{array}$ & $\begin{array}{l}\text { 1. Preceding fusion or decompression surgery of the lumbar spine or } \\
\text { preceding nucleotomy of the segments of concern (also if nucleotomy } \\
\text { becomes necessary during surgery) }\end{array}$ \\
\hline $\begin{array}{l}\text { for decompression. Diagnosis must include: } \\
\text { 1. Minimum of } 3 \text { mos of conservative therapy w/out improvement } \\
\text { of symptoms }\end{array}$ & $\begin{array}{l}\text { 2. Radiographically confirmed damage of the vertebral body in the seg- } \\
\text { ment of concern in the lumbar spine (e.g., osteoporotic compression } \\
\text { fracture or because of tumors) }\end{array}$ \\
\hline $\begin{array}{l}\text { 2. Radiographic confirmation of no translational instability in main } \\
\text { segment as well as in adjacent segments (dynamic transla- } \\
\text { tional instability } \leq 3 \mathrm{~mm} \text { ) }\end{array}$ & $\begin{array}{l}\text { 3. Isthmic \& degenerative spondylolisthesis (anterolisthesis; retrolisthesis > } \\
\text { grade I) or spondylolysis (pars fracture) } \\
\text { 4. Degenerative lumbar scoliosis }\left(>25^{\circ}\right)\end{array}$ \\
\hline 3. VAS back pain score $\geq 50 \mathrm{~mm}$ (out of 100 ) & 5. Adipositas (obesity); defined \\
\hline 4. ODI score of $\geq 1$ & $\begin{array}{l}\text { 6. Pregnancy, or wish to get pregnant during the course of the study } \\
\text { 7. Known allergy to titanium \& titanium alloys }\end{array}$ \\
\hline $\begin{array}{l}\text { If necessary, additional decompression in the adjacent segment(s) } \\
\text { may be performed, avoiding any instability in the affected segment. }\end{array}$ & $\begin{array}{l}\text { 8. Florid infections-both systemic \& local } \\
\text { 9. History of severe peripheral neuropathy } \\
\text { 10. Significant peripheral vascular disease (claudicatio intermittens } \geq \text { stage }\end{array}$ \\
\hline In addition & 2b) \\
\hline $\begin{array}{l}\text { i. Hypertrophy of the facet joints \& subarticular recessus stenosis } \\
\text { in the relevant segment }\end{array}$ & $\begin{array}{l}\text { 11. Paget disease or osteomalacia or other metabolic bone disorders } \\
\text { 12. Cauda equina syndrome }\end{array}$ \\
\hline ii. Stenosis of the foramen in the relevant segment & 13. Communicable diseases, including HIV, active hepatitis \\
\hline iii. Stable retrolisthesis up to grade I verified by flexion-extension & 14. Patients who are lawfully kept in an institution \\
\hline $\begin{array}{l}\text { radiographic films } \\
\text { Mental \& physical ability of patient to follow the protocol (i.e., compli- } \\
\text { ance w/ time schedule \& treatment plan, able to fill in CRF pages \& } \\
\text { to undergo further study procedures) }\end{array}$ & $\begin{array}{l}\text { 15. Patients who, in the opinion of the investigator, will be inappropriate for } \\
\text { inclusion in this clinical trial or who will not comply w/ requirements of } \\
\text { the study } \\
\text { 16. Patients who participated in a clinical observation or therapy w/ radiog- } \\
\text { raphy during the last } 10 \mathrm{yrs}\end{array}$ \\
\hline Willing \& able to sign an informed consent & $\begin{array}{l}\text { 17. Patients who participate }(\mathrm{d}) \text { in another clinical trial (w/in the last } 4 \mathrm{wks} \text { ) } \\
\text { that might influence the safety \& effectiveness assessment of this trial }\end{array}$ \\
\hline
\end{tabular}

CRF = case report form.

The sample size and power were estimated a priori. For $\mathrm{N}=115$ per arm with 1:1 randomization, the power of $\mathrm{t}-$ tests to test superiority for a continuous variable such as the Oswestry Disability Index (ODI) with a significance level of $p<0.025$ ( $\alpha=2.5 \%, 1$-sided, superiority) is $85 \%$, assuming a medium effect size (Cohen's $\mathrm{d}=0.4$ ) and a loss to follow-up rate of approximately $13 \%$ over 24 months. In addition to hypothesis testing for individual continuous and discrete outcome measures, superiority testing was undertaken for CCS, a binary composite measure. Statistical software packages SAS version 9.4 (SAS Institute Inc.) and R version 3.4.2 (R Core Team [2017], R Foundation for Statistical Computing) were used.

\section{Device Description}

The coflex is an ILS device that is implanted between the lamina of adjacent vertebrae. The component is a $\mathrm{U}$ shape fabricated from titanium-aluminum-vanadium alloy (Fig. 1). The U is positioned horizontally, with its apex oriented anteriorly and the 2 long arms of the U paralleling the long axis of the spinal processes. The bonefacing surfaces produce an interference fit between the lamina and are ridged to provide resistance to migration. A set of 2 wings extends vertically from the superior long arm of the $\mathrm{U}$, with a second set of wings extending below the inferior long arm. Both sets of wings have serrated bone-facing surfaces, which are designed to further sta- bilize the coflex device to the superior and inferior spinous processes. The device protects the decompression by unloading the facets, maintaining index-level range of motion, and preserving postdecompression foraminal height $(\mathrm{FH})$. In the US jurisdiction, the device is indicated for use in 1- or 2-level lumbar stenosis from L-1 to L-5 in skeletally mature patients with at least moderate impairment in function, with or without back pain, and who have undergone at least 6 months of nonoperative treatment. The coflex is intended to be implanted midline between adjacent lamina of 1 or 2 contiguous lumbar motion segments. In part, the contraindications include prior fusion or decompressive laminectomy at the index level, compressive fracture, severe facet hypertrophy requiring extensive bone removal possibly creating instability, $\geq$ grade II spondylolisthesis, degenerative lumbar scoliosis with a Cobb angle $>25^{\circ}$, osteoporosis, and idiopathic back or leg pain.

\section{Surgical Technique}

In both arms of the study, surgical management began identically. General anesthesia was induced, and patients were placed prone with appropriate positioning precautions. Using a standard midline incision, an open or mini-open surgical exposure was performed with typical technique, and confirmation of operative levels was finalized. For decompression, a standard microsurgical tech- 


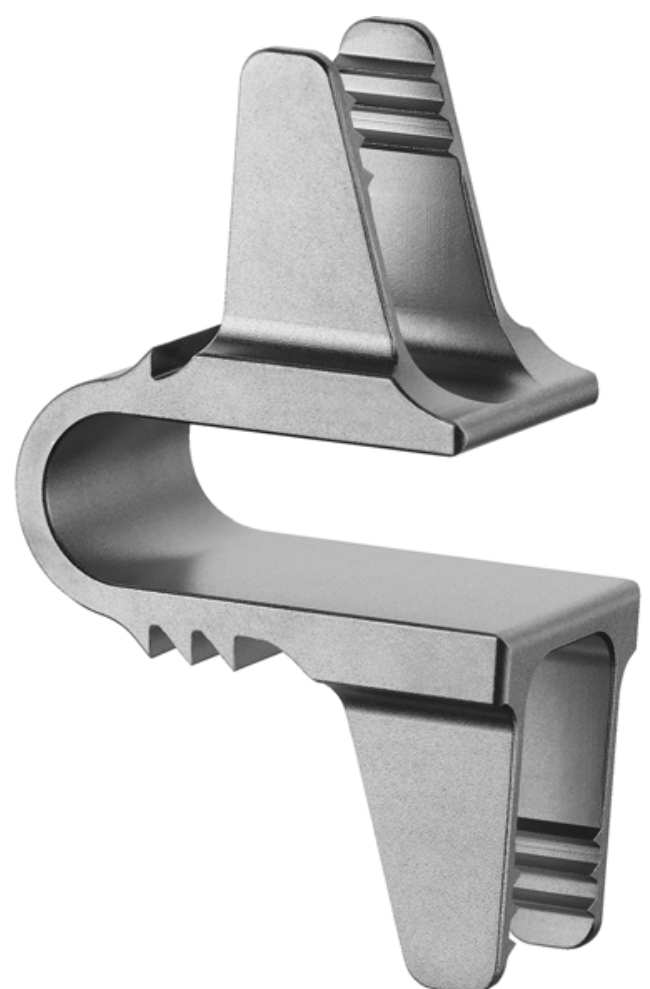

FIG. 1. Image of the ILS device. Reproduced with permission from Paradigm Spine, LLC.

nique was used. The supraspinous ligament was either resected or retracted laterally for later repair. Depending on the pathological features, partial medial facetectomies, laminotomies or laminectomies, and/or formal foraminotomies were undertaken as needed. In all cases, care was taken to preserve $50 \%$ of the bilateral facet joints and the entirety of the bilateral pars interarticularis to ensure stability. For the cases treated with coflex ILS devices, care was also taken to retain an appropriate portion of the cephalad and caudal lamina and spinous processes to allow for device purchase. Trials were then performed by inserting the coflex into the interlaminar space to confirm correct sizing-under fluoroscopic imaging, the device was introduced into the interlaminar space. After final placement, the wings were gently crimped. Fluoroscopic imaging in the anterior-posterior and lateral views was performed to confirm positioning. Standard layered closure was performed in both groups.

\section{Radiographic Outcome Measures}

Radiographic imaging was obtained at each time point. Imaging was performed at the individual sites and subsequently subjected to analyses by an independent core radiographic laboratory (Medical Metrics Inc.). Radiographic analyses focused on changes in $\mathrm{FH}$ and posterior disc height $(\mathrm{DH})$ from preoperative values.

\section{Clinical Outcome Measures}

Patients were assessed preoperatively and at 3,12, and 24 months postoperatively. Physical examination, assessment of narcotic usage, and neurological assessment were performed at each visit by the surgeon. Validated clinical outcomes were administered by patient self-assessment questionnaires that included the Zürich Claudication Questionnaire (ZCQ), VAS for back and leg pain, and the ODI. A Walking Distance Test (WDT) and radiographic evaluation were performed.

Time to secondary surgical intervention (SSI) and/or lumbar injection (LI) for pain was assessed using survival analysis methods. Criteria for SSI included removal, revision, or replacement of the study device or reoperation due to treatment failure. To provide a conservative assessment of complication relatedness, adverse events (AEs) were defined as related if they were assessed as either definitely or probably related to the implant or if the AE had a chart note indicating that it was procedure related.

\section{Walking Distance Test}

A validated treadmill-administered WDT was used to assess functional status ${ }^{4}-$ a patient would walk $\left(0^{\circ}\right.$ ramp incline at a speed of $1.8 \mathrm{~km} / \mathrm{hr}$ ) for 15 minutes $(450 \mathrm{~m})$ or until severe symptoms occurred. Clinical success was indicated by either $\geq 8$-minute improvement or the ability to walk to the maximum 15-minute limit.

\section{Patient-Reported Outcomes}

For the analysis of data, assessments only up to the time of the SSI or LI were included to avoid confounding good clinical status due to the successful secondary treatment after a failed primary treatment.

Oswestry Disability Index. The ODI is a validated questionnaire developed by Fairbank ${ }^{6}$ that is used to assess the degree of disability and the quality of life of a patient suffering from low-back pain. A validated Germanlanguage version of the ODI was used in which 1 question had been removed, comprising a 9-question instrument. The translated instrument was rescaled as 0 to 100 by dividing the sum score by 45 , and an improvement of 15 points from baseline evaluated on a per-patient basis was deemed a success. The mean improvement and the percentage of patients achieving success (improvement $>15$ points) were calculated at each time point.

Zürich Claudication Questionnaire. The ZCQ was developed by Stucki et al. ${ }^{21}$ as a quality of life index for patients with LSS, and it contains questions related to 3 distinct theoretical constructs: symptom severity (SS), physical function (PF), and patient satisfaction (PS). The $\mathrm{SS}$ domain is composed of 7 questions scored on a scale of 1-5; the PF scale is composed of 5 questions scored on a scale from 1 to 4; and the PS scale is composed of 6 questions also scored on a scale from 1 to 4 . Success in 2 or 3 ZCQ criteria was considered success.

Visual Analog Scale Score. For the analysis of VAS leg and VAS back, a decrease of at least $20 \mathrm{~mm}$ on VAS has been shown to correspond to a minimal clinically important difference and is often used for related pain assessments. For this study, VAS clinical success was defined as a $>$ 20-mm change from baseline. When evaluating VAS leg pain, separate assessments on the right and left legs were combined by evaluating whether either leg achieved at least a 20-mm improvement from baseline. 
TABLE 2. Demographics and operative characteristics in patients with LSS

\begin{tabular}{lccc}
\hline \multicolumn{1}{c}{ Variable } & D+ILS Group & DA Group* & p Value \\
\hline Sex & & & \\
\hline Male $(\%)$ & $47(42.7)$ & $57(50)$ & NA \\
\hline Female $(\%)$ & $63(57.3)$ & $57(50)$ & NA \\
\hline Age (yrs) & $68 \pm 8.8$ & $68 \pm 8.6$ & 0.969 \\
\hline BMl & $29.1 \pm 4.3$ & $29.3 \pm 4.6$ & 0.763 \\
\hline Op time (mins) & $89.7 \pm 47.2$ & $99.7 \pm 49.8$ & 0.083 \\
\hline Estimated blood loss $(\mathrm{ml})$ & $135.7 \pm 143.2$ & $160.9 \pm 154.0$ & 0.219 \\
\hline
\end{tabular}

$\mathrm{NA}=$ not applicable

Mean values are presented \pm SD.

* Baseline data were missing in 1 patient.

\section{Composite Clinical Success}

As the decision to treat a patient is multifactorial, the assessment of success must comprehensively account for the components of spinal stenosis as well. The CCS is a binary outcome measure in which all 4 components must be achieved: 1) ODI success with improvement $>15$ points; 2) survivorship with no SSIs or LIs; 3) neurological maintenance or improvement without worsening; and 4) no device- or procedure-related severe AEs (DPR SAEs). The CCS is a strict outcome measure validated in a major US FDA pivotal randomized controlled trial of the coflex device. It was the primary outcome measure resulting in regulatory approval. Results have been reported in peerreviewed publications at 2-year and 5-year follow-up. ${ }^{3,16}$

\section{Results}

\section{Demographic and Baseline Data}

Overall demographic and intraoperative measurements showed no statistically significant differences between treatment groups (Table 2). One patient in the ef- fectiveness analysis set was missing baseline data. The number of levels treated was not significantly different between groups (D+ILS: 74 single, 36 multiple; DA: 76 single, 39 multiple; $p=0.84$ ). The rate of spondylolisthesis was not significantly different (D+ILS: $22.1 \%$; DA: $22.0 \% ; \mathrm{p}=0.986)$. The baseline scores for back pain (D+ILS: $64.7 \pm 21.1$; DA: $65.4 \pm 19.6 ; \mathrm{p}=0.788$ ); left leg pain (D+ILS: $50.4 \pm 28.0$; DA: $45.3 \pm 30.6 ; \mathrm{p}=0.196$ ); and right leg pain (D+ILS: $46.2 \pm 31.9$; DA: $42.8 \pm 29.7$; $=0.411$ ) were not significantly different. The rate of central stenosis, central plus foraminal stenosis, central plus lateral recess stenosis, and central plus both foraminal and lateral recess stenosis was not significantly different between groups $(\mathrm{p}=0.747)$.

\section{Patient Follow-Up}

The analysis set consisted of 225 patients (110 D+ILS, 115 DA). There was 1 unrelated patient death in the D+ILS group. At 24 months, 101 of 109 (92.7\%) remaining patients in the D+ILS group and 103 of 115 (89.6\%) in the DA group were evaluable for analysis, representing an overall $91 \%$ follow-up rate. Major safety and efficacy end points are synopsized in Table 3.

\section{ODI Values}

Baseline ODI values for the 2 treatment groups were not different (D+ILS: $53.7 \pm 9.7$; DA: $53.3 \pm 10.3$; $\mathrm{p}=$ $0.74)$. The a priori study end point of ODI at 24 months when uncensored for subsequent secondary intervention showed no statistical difference between groups (D+ILS: $24.8 \pm 16.5$; DA: $28.0 \pm 19.8 ; \mathrm{p}=0.22$ ). At 24 months, among patients with no secondary intervention, there was no difference between the treatment groups (D+ILS: 22.8 \pm 15.9; DA: $24.6 \pm 18.8 ; \mathrm{p}=0.51$ ) (Fig. 2). At 24 months, among patients with no secondary intervention, a higher percentage of patients in the D+ILS group achieved ODI success with improvement $>15$ points (D+ILS: 75.6\%;

TABLE 3. Survival analysis and CCS in 225 patients with LSS

\begin{tabular}{|c|c|c|c|c|c|c|c|c|c|}
\hline \multirow[b]{2}{*}{ Status } & \multicolumn{3}{|c|}{ D+ILS Group } & \multicolumn{3}{|c|}{ DA Group } & \multicolumn{3}{|c|}{ Significance } \\
\hline & $\mathrm{N}$ & $\mathrm{n}$ & $\%$ & $\mathrm{~N}$ & $\mathrm{n}$ & $\%$ & $p$ Value & $95 \% \mathrm{Cl}$ & $\% \Delta$ \\
\hline $\begin{array}{l}\text { No secondary surgery at index level (reop, revision, } \\
\text { removal, supplemental fixation) }\end{array}$ & 110 & 96 & 87.3 & 115 & 98 & 85.2 & 0.655 & $-6.9 \%, 11.0 \%$ & 2.1 \\
\hline $\begin{array}{l}\text { No epidural steroid injection, facet injection, or nerve } \\
\text { root block at any lumbar level }\end{array}$ & 110 & 105 & 95.5 & 115 & 98 & 85.2 & 0.010 & $2.7 \%, 17.8 \%$ & 10.2 \\
\hline No SSI or LI & 110 & 91 & 82.7 & 115 & 84 & 73.0 & 0.081 & $-1.1 \%, 20.4 \%$ & 9.7 \\
\hline No month 24 oral narcotic pain medication & 96 & 80 & 83.3 & 100 & 77 & 77.0 & 0.267 & $-4.8 \%, 17.5 \%$ & 6.3 \\
\hline No persistent new or increasing neurological deficit & 96 & 88 & 91.7 & 100 & 89 & 89.0 & 0.528 & $-5.6 \%, 10.9 \%$ & 2.7 \\
\hline \multicolumn{10}{|l|}{ Patients meeting the survival end point (no SSI or LI) } \\
\hline ODI success & 82 & 62 & 75.6 & 71 & 50 & 70.4 & 0.470 & $-8.9 \%, 19.3 \%$ & 5.2 \\
\hline ZCQ success (2 of 3 components) & 81 & 65 & 80.2 & 71 & 58 & 81.7 & 0.821 & $-13.9 \%, 11.1 \%$ & -1.4 \\
\hline VAS leg pain success (either leg) & 82 & 70 & 85.4 & 71 & 54 & 76.1 & 0.143 & $-3.2 \%, 21.8 \%$ & 9.3 \\
\hline VAS back pain success & 82 & 57 & 69.5 & 71 & 53 & 74.6 & 0.481 & $-19.3 \%, 9.1 \%$ & -5.1 \\
\hline Walking treadmill success & 74 & 54 & 73.0 & 60 & 44 & 73.3 & 0.963 & $-15.4 \%, 14.7 \%$ & -0.4 \\
\hline $\operatorname{CCS}^{*}$ & 101 & 59 & 58.4 & 103 & 43 & 41.7 & 0.017 & $3.1 \%, 30.2 \%$ & 16.7 \\
\hline
\end{tabular}

* The CCS was calculated as ODI + no neurological deficit + no DPR SAE. 


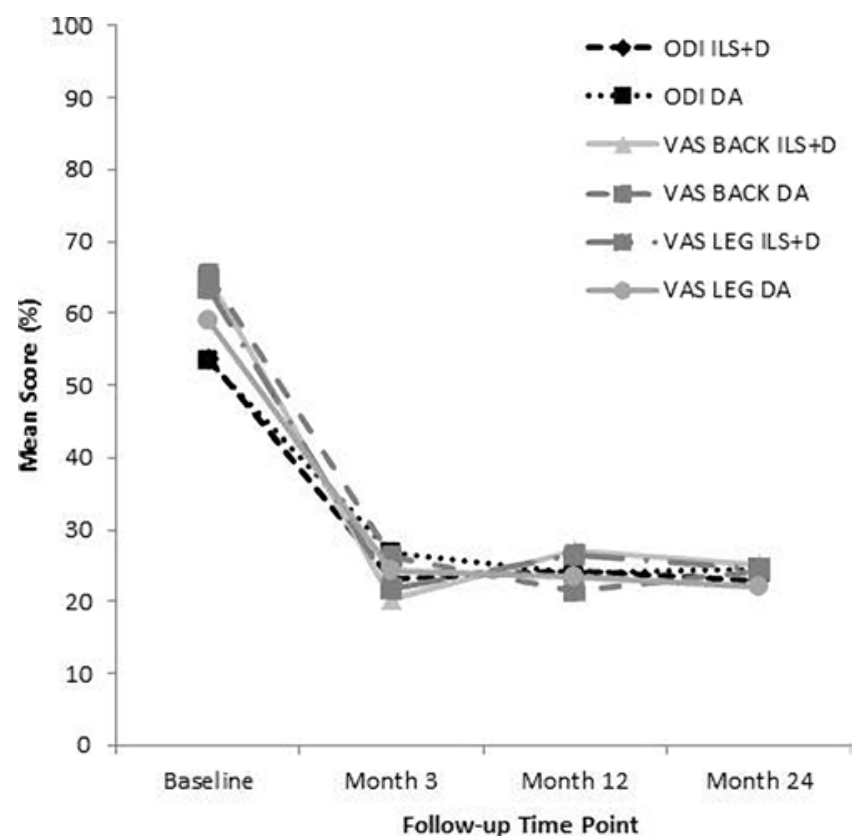

FIG. 2. Graph showing PROs in both groups. ILS+D = D+ILS.

DA: $70.4 \%$; $=0.47$ )-however, the results were not statistically different.

\section{ZCQ Success}

Among patients with no secondary intervention, 80.2\% in the D+ILS and $81.7 \%$ in the DA group achieved success criteria in at least 2 of the 3 ZCQ component scores. The group difference was not statistically significant between treatments $(\mathrm{p}=0.82)$ at month 24 . Within each component of the ZCQ (SS, PF, and PS), there was not a statistically significant difference between treatment groups at any time postoperatively.

\section{VAS Back Pain}

Among patients with no secondary intervention, $69.5 \%$ in the D+ILS and $74.6 \%$ in the DA group reported at least a 20$\mathrm{mm}$ improvement from baseline to month 24 in back pain VAS ( $p=0.48)$. Regardless of treatment, patients showed statistically significant improvements from baseline at all time points out to 24 months; however, there was no difference between treatments at any of the time points (Fig. 2).

\section{VAS Leg Pain}

Regardless of treatment, patients showed statistically significant differences from baseline at all time points out to 24 months; however there was no difference between treatments at any of the time points (Fig. 2). Among patients with no secondary intervention, $85.4 \%$ who underwent D+ILS and $76.1 \%$ who received DA $(p=0.14)$ reported at least a $20-\mathrm{mm}$ improvement in leg pain from baseline to month 24 .

\section{Secondary Intervention}

Surgical Intervention

For D+ILS, 14/110 (12.7\%) patients had an SSI. Similar-

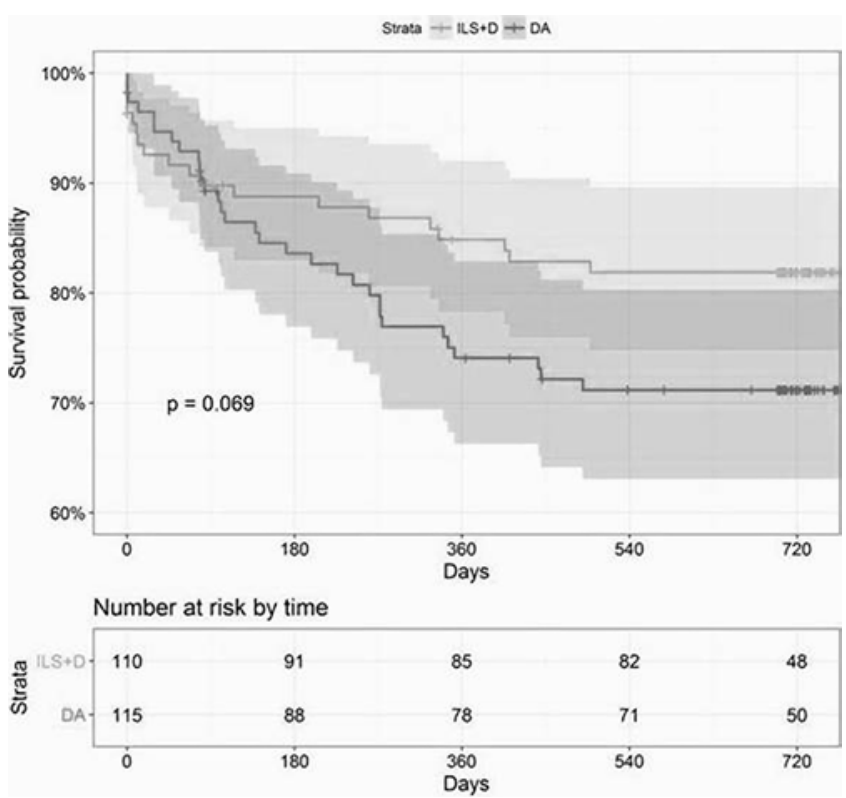

FIG. 3. Kaplan-Meier survival curve.

ly, for DA, 17/115 (14.8\%) had an SSI. For D+ILS, KaplanMeier estimates of 1- and 2-year survival without SSI were $87.7 \%$ (95\% CI 81.6\%-94.2\%) and 86.7\% (95\% CI 80.4\%93.4\%), respectively. For DA, 1- and 2-year survival estimates without SSI were $87.0 \%$ (95\% CI 80.9\%-93.6\%) and $84.1 \%$ (95\% CI 77.4\%-91.3\%), respectively. Although survival without SSI was numerically higher at 1 and 2 years for D+ILS compared with DA, the group difference was not statistically significant (log-rank test, $\mathrm{p}=0.72$ ).

\section{Epidural Steroid Injections}

Among patients with D+ILS, 5/110 (4.5\%) had an LI. For those treated with DA, 17/115 (14.8\%) had an LI at up to 2 years, and 2 additional patients in the DA group were treated with LI after month 24. No patient had an SSI prior to an LI. Three patients in the DA group had an SSI after receiving LI treatment. The group difference in time to LI was highly statistically significant $(\mathrm{p}=0.0065)$, with patients in the DA group receiving treatment sooner. The survival curve differences appeared early. At 3 months the Kaplan-Meier estimates for being injection free were 99.0\% (95\% CI 96.9\%-100\%) and 93.5\% (95\% CI 88.9\%98.3\%) for D+ILS and DA, respectively, whereas at 1 year these values were $96.8 \%$ (95\% CI 93.2\%-100\%) and $84.4 \%$ (95\% CI $77.6 \%-91.7 \%$ ), a difference of $>12 \%$.

\section{Times From Index Surgery to Secondary Intervention}

The Kaplan-Meier estimates for freedom from any secondary intervention including either SSI or LI were $84.9 \%(95 \%$ CI $78.3 \%-92.0 \%)$ at year 1 and $81.9 \%(95 \%$ CI $74.8 \%-89.6 \%$ ) at year 2 for D+ILS; and the estimates were $74.1 \%$ (95\% CI 66.3\%-82.9\%) at year 1 and $71.2 \%$ (95\% CI 63.1\%-80.3\%) at year 2 for DA. The Kaplan-Meier survival curves for times to first secondary intervention using all available follow-up data are compared in Fig. 3. The log-rank $\mathrm{p}$ value for the group difference is $\mathrm{p}=0.069$. In a multivariable proportional hazards regression model 
TABLE 4. Opioid use

\begin{tabular}{|c|c|c|c|c|c|c|c|}
\hline \multirow[b]{2}{*}{ Time Point } & \multicolumn{3}{|c|}{ D+ILS Group } & \multicolumn{3}{|c|}{ DA Group } & \multirow{2}{*}{$\begin{array}{c}p \\
\text { Value }\end{array}$} \\
\hline & $\mathrm{N}$ & $n$ & $\%$ & $\mathrm{~N}$ & $\mathrm{n}$ & $\%$ & \\
\hline Pretreatment & 110 & 35 & 31.8 & 115 & 36 & 31.3 & 0.999 \\
\hline Postsurgery & 109 & 68 & 62.4 & 115 & 77 & 67.0 & 0.488 \\
\hline Month 3 & 95 & 12 & 12.6 & 102 & 22 & 21.6 & 0.131 \\
\hline Month 12 & 91 & 14 & 15.4 & 93 & 18 & 19.4 & 0.561 \\
\hline Month 24 & 96 & 16 & 16.7 & 100 & 23 & 23.0 & 0.288 \\
\hline
\end{tabular}

controlling for age, body mass index (BMI), baseline ODI, and sex, the risk of secondary intervention was $1.75(95 \%$ CI 0.99-3.09) times higher among patients in the DA compared with those in the D+ILS group $(p=0.055)$.

\section{Narcotic Use}

Preoperatively, there was no statistically significant difference between patient groups. At every time point, from postsurgery through month 24, a lower percentage of patients in the D+ILS group reported use of opioid medication. At month 24, 16.7\% of the D+ILS and $23 \%$ of the DA group $(p=0.29)$ remained on opioid medication (Table 4$)$. The compensatory effect of narcotics usage was analyzed with respect to VAS leg pain change from preoperative baseline. Within the D+ILS group at month 24 , there was no statistically significant difference between patients taking narcotics and those not taking narcotics (VAS leg pain score for D+ILS with narcotics: $31.0 \pm 32.3$; score for D+ILS without narcotics: $23.7 \pm 26.3 ; \mathrm{p}=0.43$ ). In comparison, for the DA group at month 24 there was a statistically significant difference between patients taking narcotics compared with those not taking narcotics (VAS leg pain score for DA with narcotics: $42.7 \pm 32.5$; score for DA without narcotics: 16.9 $\pm 23.8 ; \mathrm{p}<0.01)$. Furthermore, in the DA with narcotics group, the change from baseline to month 24 decreased initially (at month 3), but increased from month 6 to month 24 to past the original baseline level. Comparatively, both D+ILS groups and the DA group without narcotics showed sustained significant decreases, from 20 to 40 points from baseline pain levels, at all postoperative time points.

\section{WDT Success}

There was no statistical difference in the preoperative median scores (D+ILS: 1.55 minutes; DA: 1.75 minutes; $\mathrm{p}=0.45)$. Among patients with no secondary intervention, $73.0 \%$ in the D+ILS and $73.3 \%$ in the DA group $(p=0.96)$ achieved the WDT success criterion of either an improvement of at least 8 minutes or being able to walk the maximum of 15 minutes. However, the comparison between treatments is significantly different when comparing the median change from baseline; D+ILS is $>2$ times the improvement of DA and $>5$ times the improvement from baseline, compared with 2 times the improvement from baseline for DA. There were statistically significant differences between treatments in median improvements at month $3(\mathrm{p}=$ $0.004)$, month $12(\mathrm{p}=0.008)$, and trending at month $24(\mathrm{p}=$ 0.06) when comparing the change from baseline (Fig. 4).

\section{Neurological Success}

Neurological success was defined as no new or worsening persistent neurological deficit in sensory, motor, or reflex function, or Laségue test (straight leg raise). At 24 months, overall neurological success was achieved in $91.7 \%$ of patients in the D+ILS versus $89.0 \%$ of those in the DA group, and the difference was not statistically significant $(p=0.53)$. There was also no difference in any of the component tests between treatments that comprised the over-

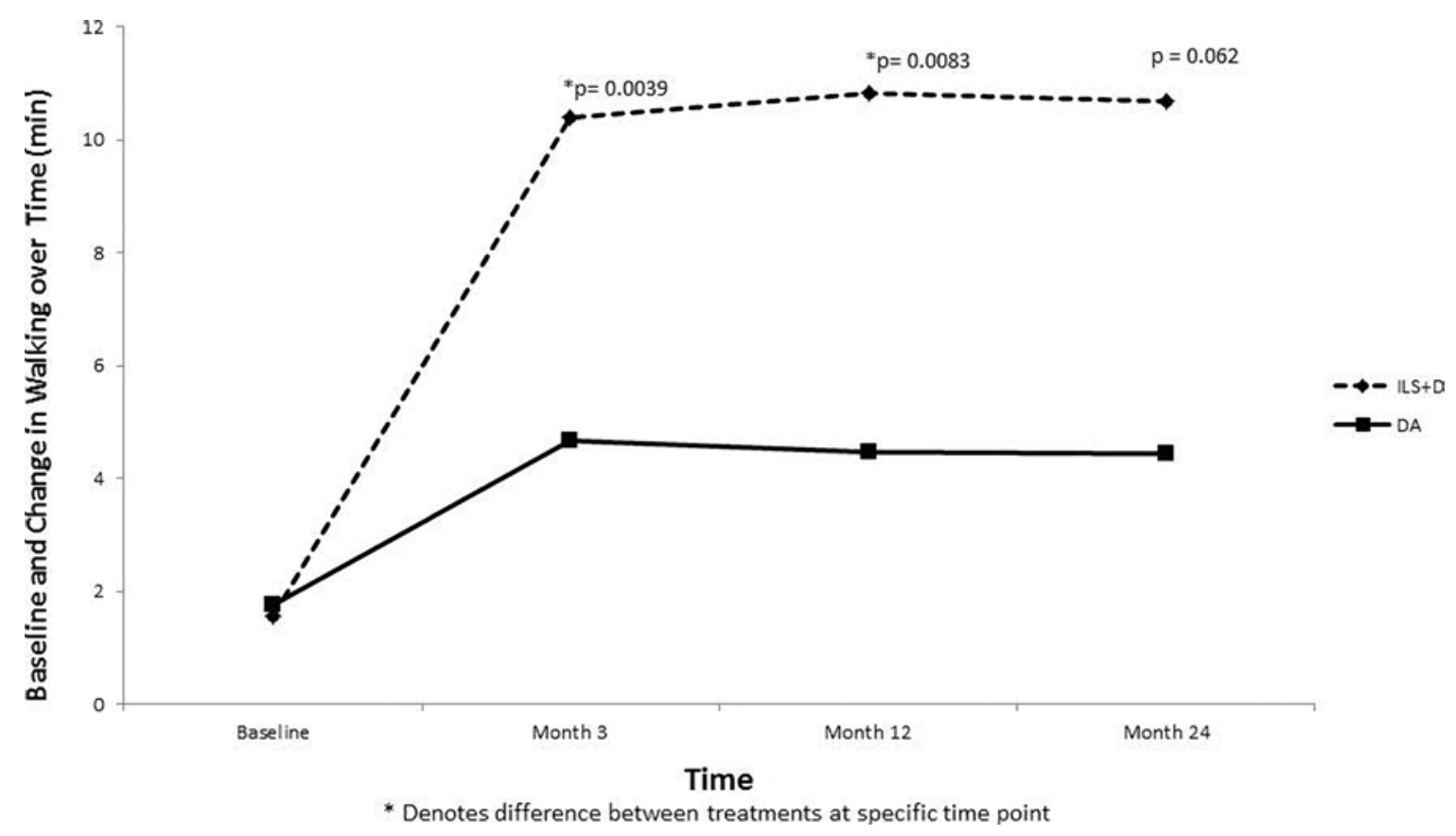

FIG. 4. Median WDT scores over time. 


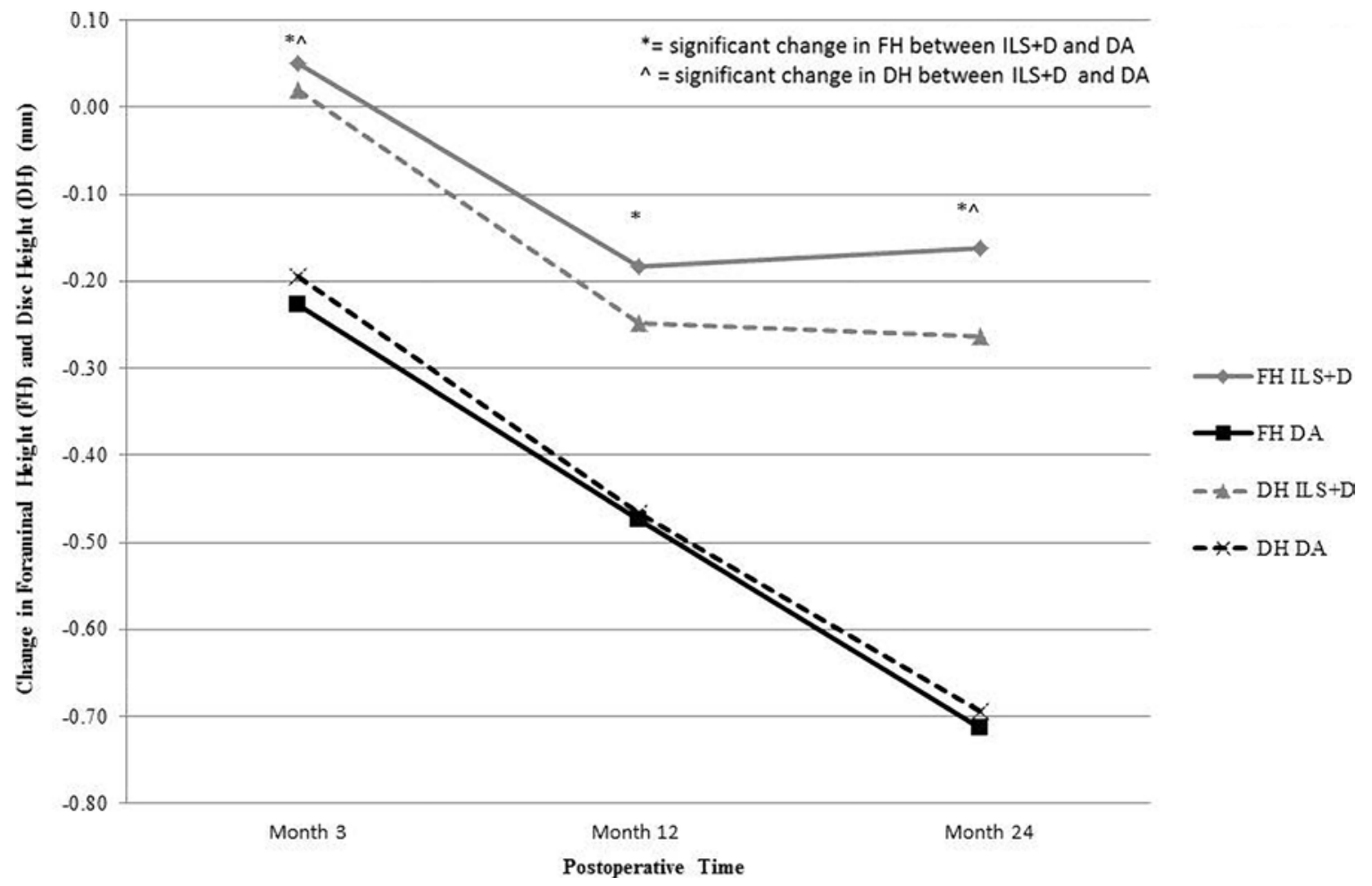

FIG. 5. Graph showing the mean change in FH and DH versus time.

all neurological success. At month 24, when neurological success and freedom from narcotics are combined with no secondary interventions and ODI success, clinical success is achieved in $55.4 \%$ of patients in the D+ILS group compared with $36.3 \%$ in the DA group $(\mathrm{p}=0.006)$, resulting in an effectiveness difference of $19.2 \%$ (95\% CI 5.7\%-32.6\%).

\section{Composite Clinical Success}

The CCS was calculated as a binary outcome measure. All 4 components must be achieved: 1) ODI success with improvement > 15 points; 2) survivorship with no SSIs or LIs; 3) neurological maintenance or improvement without worsening; and 4) no DPR SAEs. The rate of CCS was significantly superior in the stabilization group $(58.4 \%$ D+ILS vs $41.7 \%$ DA; $p=0.017$ ).

\section{Radiographic Findings}

The change in FH for D+ILS from baseline to 24 months showed a slight decrease of $0.11 \pm 0.78 \mathrm{~mm}$, which was not statistically different $(\mathrm{p}=0.16)$. In comparison, the DA group sustained a statistically significant loss of FH at all time points postoperatively, with a decrease of $0.74 \pm 1.08 \mathrm{~mm}$ at month $24(\mathrm{p}<0.001)$. The difference in the change in FH was statistically significantly different between treatment groups at month $3(\mathrm{p}=0.028)$, month $12(\mathrm{p}=0.010)$, and month $24(\mathrm{p}<0.001)$ (Fig. 5).

The preoperative DH was not significantly different (D+ILS: $4.94 \pm 1.75 \mathrm{~mm}$; DA: $4.99 \pm 1.83 \mathrm{~mm} ; \mathrm{p}=$ $0.82)$. There was statistically significantly more loss in DH at month $12(\mathrm{p}=0.041)$ and month $24(\mathrm{p}<0.001)$ from preoperative values in the DA group compared with the D+ILS group. The DA group had a 3 times greater loss
$(-0.72 \pm 1.04 \mathrm{~mm})$ than the D+ILS group $(-0.22 \pm 0.76$ $\mathrm{mm})$ at month 24 ; however, both were statistically different from the preoperative heights $(\mathrm{p}<0.001$ and $\mathrm{p}=0.006$ for DA and D+ILS, respectively) (Fig. 5).

\section{Adverse Events}

The percentages of patients with any AEs were 71.8\% (79/110) and 70.4\% (81/115) for D+ILS and DA groups, respectively $\left(\chi^{2}=0.82\right)$. Twenty-five of $110(22.7 \%)$ patients who underwent D+ILS and 26 of $115(22.6 \%)$ who had $\mathrm{DA}$ experienced an AE that was classified as related to the surgical procedure or the device $(\mathrm{p}=0.98)$. There were no DPR SAEs involving device failure or migration in the experimental arm. Dural violations were reported in $5(4.5 \%)$ patients in the D+ILS group and in 15 (13.0\%) patients in the DA group. The risk of dural violation was significantly higher $\left(\chi^{2}=0.025\right)$ in the DA group.

\section{Discussion}

Spinal stenosis is a multifactorial degenerative process, and an accurate clinical picture includes a broad analysis of clinically evaluated debilitation, patient assessment, and anatomical changes. Most surgeons agree that open, visualized, microsurgical decompression significantly improves symptoms in patients with moderate to severe claudication of spinal stenosis. However, the underlying pathology of significantly degenerated facets and subarticular disease remains.

The results of the study did not show statistically significant differences of individual patient-reported data in the 2 treatment groups among those who met the survival 
end point. The ODI group mean improvement primary end point, which included all patients and was not screened for SSIs or LIs, did not show a significant difference between treatments. Of particular note, VAS back outcomes did not show a difference because this was an expected treatment difference in the original study design. In contrast, the CCS was significantly superior for the ILS group, taking into account multiple validated safety and efficacy end points, despite the lack of difference for individual PROs. Significantly more patients in the DA group received an LI compared with those in the D+ILS group. Furthermore, this study revealed a significantly greater improvement in walking distance for the D+ILS than for the DA patient cohort, a > 2-fold difference. Radiographically, the compensatory progression of the underlying pathology was evident in both treatments; however, ILS was able to sustain the FH statistically significantly higher and longer than in the DA group. The dural tear rate was $>2$ times higher in the DA group, a rate consistent with that of other studies, $7,8,18,23$ and possibly resulting from small differences in surgical technique due to the surgeon's knowledge that the device will maintain the established decompression.

Regarding the use of CCS as an end point, most recent spine clinical trials have used such a multiple-components statistical analysis..$^{1,3,16}$ As described by Wertli et al., ${ }^{23}$ clinical interpretation bias can occur when viewing results by a single measure, because single end points do not always provide a contextually relevant viewpoint. In patients meeting the survival end point, an overall analysis was performed to be inclusive of all the factors contributing to the clinical complexity of spinal stenosis and its surgical treatment, including both safety and efficacy. Therefore, to meet the CCS criteria, a patient must survive without SSI or LI, must have a clinically important improvement in ODI score, and must have no neurological deterioration or DPR SAEs. This is a stringent clinical criterion applied to both the experimental and control arms, having previously been validated in a US FDA pivotal trial.

Although there have been previously reported studies involving coflex, this is the first level 1 study directly assessing the outcome difference of adding an ILS device postdecompression compared with DA. Röder et al. ${ }^{19}$ noted significant benefit with coflex stabilization after decompression in a matched-pair cohort comparison study from the Swiss Spine Registry and the European Spine Tango database. Kumar et al. ${ }^{12}$ reported statistically significant improvement with open microsurgical decompression for spinal stenosis and statistically significant improvement when coflex ILS was added to the decompression. Furthermore, although not comparing the procedure with ILS, Budithi et al. ${ }^{2}$ demonstrated the importance of evaluating walking distance in patients with spinal stenosis undergoing decompression surgery. Combining these experiences with the level 1 data of the investigational device exemption study findings, ${ }^{1,3,16}$ there is evidence that ILS surgery has a valid place in the treatment of spinal stenosis.

Historically, interspinous distraction devices were developed as a potential alternative to decompression procedures. The literature has demonstrated that one cannot ask a device to do the job of a surgery with sustainable or durable outcomes. Moojen et al. ${ }^{15}$ studied DA compared with
ILS device insertion without a concomitant decompression and validated the need for a decompression procedure as an essential requirement of any LSS surgical treatment option. Richter et al..$^{18}$ showed no difference at 24 months between D+ILS and DA in mean outcomes; however, the relative individual patient outcomes were not reported. In addition, significant limitations of the study were selection bias, resulting in clinically meaningful differences in ODI baseline scores; the nonrandomized nature of their results; and the surgeons' determination of treatment choice (device insertion or not) intraoperatively.

This study has several limitations. Despite being a randomized clinical trial, imperfections in its conduct mean that some patients were lost to follow-up and there were some missing data. Despite these unavoidable challenges, the overall follow-up rate was satisfactory for a spinal surgical trial. Also, any randomized trial that is industry sponsored raises the question of bias, even if the bias is unintentional. However, this possibility was mitigated in the trial design by focusing on empirical and objective measures (e.g., radiographic parameters, walking distance) as well as PROs that are not subject to reporter bias.

\section{Conclusions}

Our study showed no significance of the individual PROs (e.g., ODI, VAS, ZCQ) between the treatments when viewed in isolation. However, the CCS, an end point validated in a US FDA pivotal trial that combines 4 safety and efficacy end points, is statistically superior for ILS. The DA arm had 228\% more LIs and had a numerically higher rate of narcotic use at every time point postsurgically. Microsurgical D+ILS increases walking tolerance, decreases compensatory pain management, and maintains radiographic $\mathrm{FH}$, extending the durability and sustainability of a decompression procedure.

\section{Acknowledgments}

We thank the other clinical investigators, the institutions, and most importantly, the patients who participated in this study. The following institutions provided patients for this study: 1) Orthopädische Universitätsklinik, Frankfurt; 2) Klinikum Magdeburg; 3) Paracelsusklinik Henstedt-Ulzburg, Wirbelsäulenchirurgie; 4) Universitätsklinikum Schleswig-Holstein Klinik für Neurochirurgie, Lubeck; 5) Chirurgische Universitätsklinik Rostock; 6) Klinik für Wirbelsäulenchirurgie mit Skoliosezentrum, Klinikum Neustadt; and 7) Oberlinklinik Potsdam, Germany.

\section{References}

1. Bae HW, Lauryssen C, Maislin G, Leary S, Musacchio MJ Jr: Therapeutic sustainability and durability of coflex interlaminar stabilization after decompression for lumbar spinal stenosis: a four year assessment. Int J Spine Surg 9:15, 2015

2. Budithi S, Dhawan R, Cattell A, Balain B, Jaffray D: Only walking matters-assessment following lumbar stenosis decompression. Eur Spine J 26:481-487, 2017

3. Davis RJ, Errico TJ, Bae H, Auerbach JD: Decompression and Coflex interlaminar stabilization compared with decompression and instrumented spinal fusion for spinal stenosis and low-grade degenerative spondylolisthesis: two-year results from the prospective, randomized, multicenter, Food and Drug Administration Investigational Device Exemption trial. Spine (Phila Pa 1976) 38:1529-1539, 2013 
4. Deen HG Jr, Zimmerman RS, Lyons MK, McPhee MC, Verheijde JL, Lemens SM: Measurement of exercise tolerance on the treadmill in patients with symptomatic lumbar spinal stenosis: a useful indicator of functional status and surgical outcome. J Neurosurg 83:27-30, 1995

5. Deyo RA, Mirza SK, Martin BI, Kreuter W, Goodman DC, Jarvik JG: Trends, major medical complications, and charges associated with surgery for lumbar spinal stenosis in older adults. JAMA 303:1259-1265, 2010

6. Fairbank J: Use of Oswestry Disability Index (ODI). Spine (Phila Pa 1976) 20:1535-1537, 1995

7. Försth P, Ólafsson G, Carlsson T, Frost A, Borgström F, Fritzell P, et al: A randomized, controlled trial of fusion surgery for lumbar spinal stenosis. N Engl J Med 374:1413-1423, 2016

8. Ghogawala Z, Dziura J, Butler WE, Dai F, Terrin N, Magge $\mathrm{SN}$, et al: Laminectomy plus fusion versus laminectomy alone for lumbar spondylolisthesis. N Engl J Med 374:14241434,2016

9. Guyer R, Musacchio M, Cammisa FP Jr, Lorio MP: ISASS recommendations/coverage criteria for decompression with interlaminar stabilization - coverage indications, limitations, and/or medical necessity. Int J Spine Surg 10:41, 2016

10. Kim HJ, Jeong JH, Cho HG, Chang BS, Lee CK, Yeom JS: Comparative observational study of surgical outcomes of lumbar foraminal stenosis using minimally invasive microsurgical extraforaminal decompression alone versus posterior lumbar interbody fusion: a prospective cohort study. Eur Spine J 24:388-395, 2015

11. Kleinstück FS, Grob D, Lattig F, Bartanusz V, Porchet F, Jeszenszky D, et al: The influence of preoperative back pain on the outcome of lumbar decompression surgery. Spine (Phila Pa 1976) 34:1198-1203, 2009

12. Kumar N, Shah SM, Ng YH, Pannierselvam VK, Dasde S, Shen L: Role of Coflex as an adjunct to decompression for symptomatic lumbar spinal stenosis. Asian Spine J 8:161-169, 2014

13. Lee CH, Hyun SJ, Kim KJ, Jahng TA, Kim HJ: Decompression only versus fusion surgery for lumbar stenosis in elderly patients over 75 years old: which is reasonable? Neurol Med Chir (Tokyo) 53:870-874, 2013

14. Modhia U, Takemoto S, Braid-Forbes MJ, Weber M, Berven $\mathrm{SH}$ : Readmission rates after decompression surgery in patients with lumbar spinal stenosis among Medicare beneficiaries. Spine (Phila Pa 1976) 38:591-596, 2013

15. Moojen WA, Arts MP, Jacobs WC, van Zwet EW, van den Akker-van Marle ME, Koes BW, et al: Interspinous process device versus standard conventional surgical decompression for lumbar spinal stenosis: randomized controlled trial. BMJ 347:f6415, 2013

16. Musacchio MJ, Lauryssen C, Davis RJ, Bae HW, Peloza JH, Guyer RD, et al: Evaluation of decompression and interlaminar stabilization compared with decompression and fusion for the treatment of lumbar spinal stenosis: 5-year follow-up of a prospective, randomized, controlled trial. Int J Spine Surg 10:6, 2016

17. Omidi-Kashani F, Hasankhani EG, Ashjazadeh A: Lumbar spinal stenosis: who should be fused? An updated review. Asian Spine J 8:521-530, 2014

18. Richter A, Schütz C, Hauck M, Halm H: Does an interspinous device $\left(\mathrm{Coflex}{ }^{\mathrm{TM}}\right)$ improve the outcome of decompressive surgery in lumbar spinal stenosis? One-year follow up of a prospective case control study of 60 patients. Eur Spine J 19:283-289, 2010

19. Röder C, Baumgärtner B, Berlemann U, Aghayev E: Superior outcomes of decompression with an interlaminar dynamic device versus decompression alone in patients with lumbar spinal stenosis and back pain: a cross registry study. Eur Spine J 24:2228-2235, 2015

20. Sigmundsson FG, Jönsson B, Strömqvist B: Outcome of decompression with and without fusion in spinal stenosis with degenerative spondylolisthesis in relation to preoperative pain pattern: a register study of 1,624 patients. Spine J 15:638-646, 2015

21. Stucki G, Daltroy L, Liang MH, Lipson SJ, Fossel AH, Katz $\mathrm{JN}$ : Measurement properties of a self-administered outcome measure in lumbar spinal stenosis. Spine (Phila Pa 1976) 21:796-803, 1996

22. Weinstein JN, Tosteson TD, Lurie JD, Tosteson AN, Blood E, Hanscom B, et al: Surgical versus nonsurgical therapy for lumbar spinal stenosis. N Engl J Med 358:794-810, 2008

23. Wertli MM, Buletti FC, Held U, Rasmussen-Barr E, Weiser S, Burgstaller JM, et al: A comparison between different outcome measures based on "meaningful important differences" in patients with lumbar spinal stenosis. Eur Spine J 26:450-461, 2017

\section{Disclosures}

Dr. Bonsanto receives clinical or research support for the study described (includes equipment or material) from Paradigm Spine. Dr. Franke is a consultant for Medtronic, EIT, Zimmer; holds a patent with Medacta; receives support of a non-studyrelated clinical or research effort that he oversees from Baxter and EOS Imaging, and clinical or research support for the study described (includes equipment or material) from Paradigm Spine. Dr. Rauschmann holds a patent with Aesculap; is a consultant for Aesculap, Medacta, Biomet, Zimmer, Spontech, and Paradigm Spine; and receives clinical or research support for the study described (includes equipment or material) from Aesculap, Medacta, Nanobone, and Paradigm Spine.

The study was funded by Paradigm Spine, the manufacturer of the coflex ILS device used in the study. The following fees/payments were paid to the study sites as of May 31, 2017: Damp 15,005 $€$; Frankfurt 40,385 €; Magdeburg 10,250 €; Potsdam 2,195€; Rostock 101,515 €; Neustadt 2,763€; and Lubeck $0 €$. In total, $172,113 €$ has been paid to these sites as of May 31, 2017. In addition to these fees, investigators from this study have received a total of $164,413 €$ from Paradigm Spine since 2008 in general consulting fees that were unrelated to the current study: Dr. Rauschmann received 53,900 €; Dr. Franke received 81,713 €; Dr. Reinhardt received 5,800 €; and Dr. Sola received 23,000 €.

\section{Author Contributions}

Conception and design: Rauschmann. Acquisition of data: all authors. Analysis and interpretation of data: all authors. Drafting the article: Rauschmann, Schmidt, Franke, Bonsanto, Sola. Critically revising the article: all authors. Reviewed submitted version of manuscript: all authors. Approved the final version of the manuscript on behalf of all authors: Rauschmann. Statistical analysis: Rauschmann. Administrative/technical/material support: Rauschmann. Study supervision: Rauschmann.

\section{Supplemental Information}

\section{Previous Presentations}

The information for this study was presented at the International Society for the Advancement of Spine Surgery (ISASS) meeting in 2016, Las Vegas, NV, April 6-8, and at the North American Spine Society (NASS) meeting in 2017, Orlando, FL, October $25-28$.

\section{Current Affiliations}

Drs. Schmidt and Rauschmann: Sana Klinikum Offenbach, Offenbach am Main, Hesse, Germany.

\section{Correspondence}

Michael Rauschmann: Sana Klinikum Offenbach, Offenbach am Main, Hesse, Germany.michael.rauschmann@sana.de. 